\title{
Assessment and Prevention of Dental Caries in Children Who Were on Artificial Feeding
}

\section{IJCRR}

Section: Healthcare

Sci. Journal Impact

Factor: 6.1 (2018)

ICV: 90.90 (2018)

(c) (7) (5)

Copyright@IJCRR

\section{Jalilova Fariza Rasuljanovna1, Murtazaev Saidmurodkhon Saidialoevich²}

'Basic Doctoral Student, Pediatric Dentistry Department, Tashkent State Dental Institute, Uzbekistan; ${ }^{2}$ Associate Professor \& Head,

Pediatric Dentistry Department, Doctor of Medical Sciences, Tashkent State Dental Institute, Uzbekistan.

\section{ABSTRACT}

Background: Dental caries is among the most frequently occurring dental diseases in children. In the present study, we assessed the prevention of dental caries in children who were on artificial feeding.

Methods: The present study was conducted on 1560 children age ranged 3-5 years of both genders and assessment of dental caries was done using dentition status and treatment need as per criteria laid by World Health Organization (WHO).

Results: Out of 1560 children, boys were 840 and girls were 720 . Age group 3 years had 120 boys and 160 girls, 4 years had 270 boys and 300 girls and age 5 years had 450 boys and 260 girls. Out of 840 boys, 360 had caries and out of 720 girls, 390 had caries. The mean $\mathrm{dm} \mathrm{ft}$ score in boys was $1.60 \pm 0.58$ and in girls was $1.54 \pm 0.56$. Maximum caries was seen in which age of starting of bottle feeding was $<6$ months seen in 140, 6-12 months in 180 and 1-2 years seen in 210 children. Maximum caries was seen in children in which the duration of bottle-feeding/ day was 3 hours (260), 2 hours (160) and 1 hour (160). Maximum caries was seen in children in which 1-2 tsp were added (230) followed by 1 tsp (220) and 0 tsp (80). Maximum caries was seen in children in which bottle was used throughout the night in 220, only during feed in 70 and sometimes in 50 . Maximum caries was seen in children in which frequency of tooth brushing was occasionally seen in 300, once in 440 and twice seen in 10 children. The difference was significant $(P<0.05)$. Pit and fissure sealant was used in $60 \%$ and GIC restoration in $40 \%$ of children.

Conclusion: Authors found that bottle feeding is one of the risk factors for early childhood caries. Mother care and awareness regarding child oral hygiene are of paramount importance in preventing the occurrence of dental caries.

Key Words: Bottle feeding, Dental caries, Pit, Fissure

\section{INTRODUCTION}

Dental caries is among the most frequently occurring dental diseases in children. It is the disease of calcified hard tissue characterized by destruction of organic and demineralization of the inorganic portion of the tooth. ${ }^{1}$ It has infected $60-90 \%$ of school-going children and adults. ${ }^{2}$ It is found that feeding practices have a profound role in causing dental caries. Apart from this, the intake of low fibre and high sugar is another factors. In the first few years, the breastfeeding, use of bottles for milking and complementary foods use have served as aggravating factors. ${ }^{3}$

Early childhood caries (ECC) affects the child quality of life with the increased risk of infecting permanent teeth too. ECC is considered to be a public health problem. Determinants such as socioeconomic, sociobehavioural and sociocultural are thought to be affected by specific risk factors for ECC like oral hygiene, dietary and feeding practices and dental attendance patterns. ${ }^{4}$

In India due to rapid change of lifestyle including change of dietary habits has significantly increased the dental caries incidence in children. Mothers play an important role in preventing the occurrence of dental caries in children. It is found in the literature that mothers who have insufficient knowledge about feeding habits have their child more dental caries pattern. ${ }^{5}$ In the present study we assessed the prevention of dental caries in children who were on artificial feeding.

\section{MATERIALS AND METHODS}

The present study was started after obtaining ethical approval from the ethical committee of the institute. All

\section{Corresponding Author:}

Jalilova Fariza Rasuljanovna, Basic Doctoral Student, Pediatric Dentistry Department, Tashkent State Dental Institute, Uzbekistan.

ISSN: 2231-2196 (Print)

Received: 17.07.2020
ISSN: 0975-5241 (Online)

Revised: 22.09 .2020
Accepted: 05.11 .2020
Published: 07.12 .2020 
parents of 1560 children age ranged 3-5 years of both genders were informed and their written approval was obtained (Table 1). Demographic data such as name, age, gender etc. was recorded. A questionnaire was prepared and distributed among parents regarding feeding habits such as breastfeeding duration, artificial feeding duration etc. A thorough oral examination by an expert dental surgeon was assessed dental caries using dentition status and treatment need as per criteria laid by the World Health Organization (WHO). Assessment of dental caries was done using mouth mirror, probe and explorer. Dmft status such as decayed, missing and filled teeth was recorded in all children. Results of the study were tabulated and subjected to statistical assessment using SPSS version 19 (IL, Chicago, USA). $\mathrm{P}<0.05$ value was considered significant.

\section{RESULTS}

\section{Demographic characterization}

Total 1560 children were enrolled and 840 were boys and 720 girls. Table 2 shows that age group 3 years had 120 boys and 160 girls, 4 years had 270 boys and 300 girls and age 5 years had 450 boys and 260 girls.

Table 1: Gender wise distribution of children

\begin{tabular}{lcc} 
Total-1560 & Girls \\
Gender & Boys & 720 \\
\hline Number & 840 & \\
\hline
\end{tabular}

\begin{tabular}{|c|c|c|c|}
\hline Age group (Years) & Boys & Girls & Total \\
\hline 3 & 120 & 160 & 280 \\
\hline 4 & 270 & 300 & 570 \\
\hline 5 & 450 & 260 & 710 \\
\hline Total & 840 & 720 & \\
\hline
\end{tabular}

\section{Method of prevention on dental caries}

Figure 1 shows that pit and fissure sealant was used in $60 \%$ and GIC restoration in $40 \%$ of children.

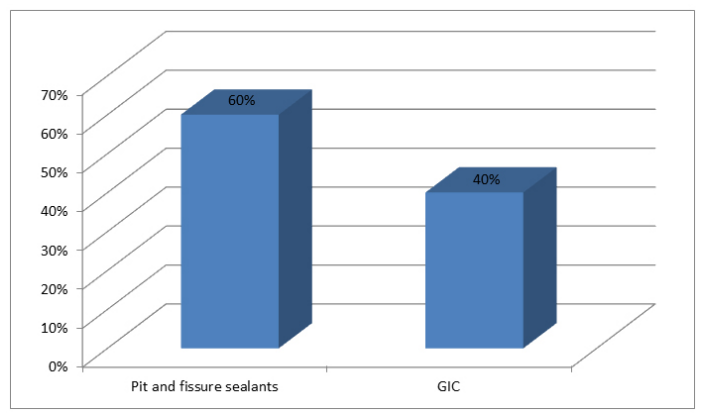

Figure 1: Method of prevention on dental caries.

\section{Prevalence of dental caries}

Table 3 shows that out of 840 boys, 360 had caries and out of 720 girls, 390 had caries. The mean dmft score in boys was $1.60 \pm 0.58$ and in girls was $1.54 \pm 0.56$. Table 4 shows that maximum caries was seen in which age of starting of bottle feeding was $<6$ months seen in 140, 6-12 months in 180 and 1-2 years seen in 210 children. Maximum caries was seen in children in which the duration of bottle-feeding/ day was 3 hours (260), 2 hours (160) and 1 hour (160). Maximum caries was seen in children in which 1-2 tsp were added (230) followed by 1 tsp (220) and 0 tsp (80). Maximum caries was seen in children in which bottle was used throughout the night in 220, only during feed in 70 and sometimes in 50 . Maximum caries was seen in children in which frequency of tooth brushing was occasionally seen in 300 , once in 440 and twice seen in 10 children. The difference was significant $(\mathrm{P}<0.05)$.

Table 3: Prevalence of dental caries

\begin{tabular}{lccc} 
Gender & Caries free & Caries affected & Dmft $($ mean \pm SD) \\
Boys & 480 & 360 & $1.60 \pm 0.58$ \\
Girls & 330 & 390 & $1.54 \pm 0.56$ \\
Total & 810 & 750 & $2.06 \pm 2.98$ \\
\hline
\end{tabular}

Table 4: Caries based on feeding habits and oral hygiene habits

\begin{tabular}{llcccc} 
Parameters & Variables & $\begin{array}{c}\text { Total } \\
\text { Caries } \\
\text { free }\end{array}$ & $\begin{array}{c}\text { Caries } \\
\text { affected }\end{array}$ & $\begin{array}{c}\text { P- } \\
\text { value }\end{array}$ \\
$\begin{array}{l}\text { Age of start- } \\
\text { ing of bottle }\end{array}$ & $<6$ months & 300 & 160 & 140 & \\
feeding & 6- 12 months & 240 & 60 & 180 & \\
& $\begin{array}{l}1-2 \text { years } \\
\text { Not intro- }\end{array}$ & 310 & 100 & 210 & 0.02 \\
& duced & 490 & 220 & \\
Duration of & 1 hour & 220 & 80 & 160 & \\
bottle feed- & 2 hour & 210 & 50 & 160 & 0.05 \\
ing/ day & 3 hour & 280 & 70 & 210 & \\
& None & 710 & 490 & 220 & \\
Sugar added & o tsp & 200 & 120 & 80 & \\
& 1 tsp & 340 & 120 & 220 & 0.04 \\
& $1-2$ tsp & 350 & 120 & 230 & \\
& No & 670 & 470 & 220 & \\
Frequency of & Throughout & 320 & 100 & 220 & \\
child & night & & & & \\
falling asleep & Only during & 180 & 110 & 70 & 0.05 \\
with bottle & feed & & & & \\
& Sometimes & 190 & 40 & 50 & \\
Frequency of & Never & 870 & 460 & 410 & \\
Once & 1020 & 580 & 440 & \\
tooth brush- & Twice & 80 & 70 & 10 & 0.01 \\
& Occasionally & 460 & 200 & 300 & \\
\hline
\end{tabular}




\section{DISCUSSION}

Dental caries pattern in high prevalence in school going children as compared to adults. The reason can be multiple. ${ }^{6}$ The high sugar intake, lack of maintenance of oral hygiene, failure to adhering to brushing by mothers, frequent and prolonged use of bottle feeding etc are few contributing risk factors. ${ }^{78}$ It is evident in many studies that children who start bottle feeding early in life tend to have more prevalence of dental caries as compared to those who start late or never. It is also demonstrated in various studies that the use of sugar mixed in milk is the leading cause of dental caries and the amount of sugar added determines the caries prevalence. ${ }^{9,10}$ The present study was conducted to determine caries prevalence and method to control it in children who were on artificial feeding. ${ }^{6,7}$

In the present study, the age group 3 years had 120 boys and 160 girls, 4 years had 270 boys and 300 girls and age 5 years had 450 boys and 260 girls. We observed that out of 840 boys, 360 had caries and out of 720 girls, 390 had caries. The mean $\mathrm{dmft}$ score in boys was $1.60 \pm 0.58$ and in girls was $1.54 \pm$ $0.56{ }^{8,9} \mathrm{~A}$ study on mothers' practices regarding feeding and oral hygiene practices and found that there was a $48 \%$ prevalence of ECC with $2.03 \pm 2.99 \mathrm{dmft}$ scores. $57 \%$ of boys and $43 \%$ girls were affected which was found to be statistically significant $(P<0.05)$. Caries prevalence was statistically significant $(P<0.05)$ and high among those who were breastfed for during nighttime, longer duration, those fed with additional sugar in milk, and those falling asleep with a bottle. ${ }^{10,11}$

We found that maximum caries was seen in which age of starting of bottle feeding was $<6$ months seen in 140, 6-12 months in 180 and 1-2 years seen in 210 children. Maximum caries was seen in children in which the duration of bottlefeeding/ day was 3 hours (260) followed by 2 hours (160) and 1 hour (160). Felden et al. ${ }^{12}$ in their study on 345 children of different age groups found that as compared to children with 12-month infrequent bottle use and breastfeeding, 38-month ECC prevalence was 1.8-times higher in children breastfed $>3$ times/day. Results showed that ECC prevalence was 1.4-times higher in children bottle-fed $>3$ times/day and 1.5-times higher with breastfeeding together and combined high frequency of bottle $(\mathrm{p}=0.04)$, but the association with consuming other foods/drinks $>5$ times/day was not statistically significant. Severe-ECC prevalence was significantly associated with frequent breastfeeding.

We observed that maximum caries was seen in children in which 1-2 tsp were added (230) followed by 1 tsp (220) and 0 tsp (80). Maximum caries was seen in children in which bottle was used throughout the night in 220 , only during feed in 70 and sometimes in 50. Maximum caries was seen in children in which frequency of tooth brushing was occasionally seen in 300 , once in 440 and twice seen in 10 children. The difference was significant $(\mathrm{P}<0.05)$.
We observed that method of caries prevention used as pit and fissure sealant in $60 \%$ and GIC restoration in $40 \%$ of children. It is found in the present study that those who were not on bottle feed had less prevalence of dental caries as compared to those who started earlier in their life. ${ }^{12}$ The shortcoming of the study is the small sample size. The type of brushing method used was not recorded.

\section{CONCLUSION}

Bottle feeding is one of the risk factors for early childhood caries. Mother care and awareness regarding child oral hygiene are of paramount importance in preventing the occurrence of dental caries.

\section{REFERENCES}

1. Park S, Lin M, Onufrak S, Li R. Association of sugar-sweetened beverage intake during infancy with dental caries in 6-year-olds. Clin Nutr Res 2015; 4:9-17.

2. Rodrigues CS, Sheiham A. The relationships between dietary guidelines, sugar intake and caries in primary teeth in low-income Brazilian 3-year-olds: a longitudinal study. Int J Paediatr Dent 2000; 10:47-55.

3. Cahuana-Vásquez RA, Tabchoury CP, Tenuta LM, et al. Effect of frequency of sucrose exposure on dental biofilm composition and enamel demineralization in the presence of fluoride. Caries Res 2007; 41:9-15.

4. Ruel MT, Menon P. Child feeding practices are associated with child nutritional status in Latin America: innovative uses of the demographic and health surveys. J Nutr 2002; 132:1180-1187.

5. Fall CH, Borja JB, Osmond C, et al. Infant-feeding patterns and cardiovascular risk factors in young adulthood: data from five cohorts in low- and middle-income countries. Int J Epidemiol 2011; 40:47-62.

6. Zhou Y, Yang JY, Lo EC, Lin HC. The contribution of life course determinants to early childhood caries: a 2-year cohort study. Caries Res 2012; 46:87-94.

7. Vítolo MR, Louzada ML, Rauber F. Positive impact of child feeding training program for primary care health professionals: a cluster randomized field trial. Rev Bras Epidemiol 2014; 17:873-886.

8. Chaffee BW, Feldens CA, Vítolo MR. Cluster-randomized trial of infant nutrition training for caries prevention. J Dent Res 2013; 92:29-36.

9. Milgrom P, Riedy CA, Weinstein P, et al. Dental caries and its relationship to bacterial infection, hypoplasia, diet, and oral hygiene in 6-to- 36-month-old children. Community Dent Oral Epidemiol 2000; 28:296-306.

10. Mohebbi SZ, Virtanen JI, Vahid-Golpayegani M, et al. Feeding habits as determinants of early childhood caries in a population where prolonged breastfeeding is the norm. Community Dent Oral Epidemiol 2008; 36:363-369.

11. Prakasha SS, Vinit GB, Giri KY, Alam S. Feeding practices and early childhood caries: a cross-sectional study of preschool children in kanpur district, India. Int Schol Res Not 2013;2013.

12. Feldens CA, Rodrigues PH, de Anastácio G, Vítolo MR, Chaffee BW. Feeding frequency in infancy and dental caries in childhood: a prospective cohort study. Int Dental J 2018 Apr;68(2):113-21. 